\title{
Chemical aspect of sodium hypochlorite activation in obtaining favorable outcomes of endodontic treatment: An in-vitro study
}

\author{
*Hubert Gołąbek ${ }^{1, A-E}$, ${ }^{*}$ Krzysztof Mariusz Borys ${ }^{2, A-E}$, Meetu Ralli Kohli, ${ }^{3, C-E}$, \\ Katarzyna Brus-Sawczuk ${ }^{1, C, E}$, Izabela Strużycka ${ }^{1, C, E, F}$ \\ ${ }^{1}$ Department of Comprehensive Dental Care, Medical University of Warsaw, Poland \\ 2 Faculty of Chemistry, Warsaw University of Technology, Poland \\ ${ }^{3}$ Department of Endodontics, University of Pennsylvania School of Dental Medicine, Philadelphia, USA \\ A - research concept and design; $B$ - collection and/or assembly of data; $C$ - data analysis and interpretation; \\ $D$ - writing the article; $E$ - critical revision of the article; $F$ - final approval of the article
}

Address for correspondence

Hubert Gołąbek

E-mail: hubert58@vp.pl

\section{Funding sources}

Krzysztof M. Borys acknowledges the Warsaw University of Technology for financial support.

Conflict of interest

None declared

\section{Acknowledgements}

The authors acknowledge the assistance of Andrzej Giniewicz, PhD Eng, from the Faculty of Pure and Applied Mathematics, Wrockaw University of Science and Technology, Poland, in the statistical analysis of the results.

* These authors contributed equally to this work.

Received on November 30, 2018

Reviewed on December 15, 2018

Accepted on February 18, 2019

Published online on August 29, 2019

Cite as

Gołąbek H, Borys KM, Kohli MR, Brus-Sawczuk K, Strużycka I. Chemical aspect of sodium hypochlorite activation in obtaining favorable outcomes of endodontic treatment: An in-vitro study. Adv Clin Exp Med. 2019;28(10):1311-1319. doi:10.17219/acem/104523

DOI

10.17219/acem/104523

Copyright

Copyright by Author(s)

This is an article distributed under the terms of the

Creative Commons Attribution Non-Commercial License

(http://creativecommons.org/licenses/by-nc-nd/4.0/)

\begin{abstract}
Background. Endodontic treatment is one of the most widely performed procedures in a dental office. New techniques for enhancing the effectiveness of irrigants are being introduced into the dental market. It is crucial to choose a proper method to obtain the highest possible long-term success of performed endodontic treatment. Sodium hypochlorite ( $\mathrm{NaOCl}$ ) appears to be one of the most common and profitable solutions for root canal irrigation. The activation of a solution may be analyzed in 2 fields, physical - turbulence of flow, and chemical - disintegration of irrigant molecules into very active radicals that improve its activity. While the physical alternations of irrigant flow with different techniques are widely studied, there are not many attempts to approach the subject in chemical terms.
\end{abstract}

Objectives. The aim of the study was to compare the chemical effectiveness of 2 methods of $\mathrm{NaOCl}$ activation: ultrasonics vs the Self-Adjusting File system (SAF) as an adjunct to increase the efficacy of the irrigant.

Material and methods. The level of activation was evaluated via a reaction of the activated $\mathrm{NaOCl} \mathrm{samples,}$ with 9-fluorenol as the starting organic material. The model reaction is based on the oxidation of 9-fluorenol to 9-fluorenon. The evaluation was performed using $1 \mathrm{H}$ nuclear magnetic resonance (NMR) spectroscopy, comparing the spectra obtained for the examined mixtures.

Results. Nuclear magnetic resonance studies show that the use of ultrasonics resulted in increased chemical degradation of $\mathrm{NaOCl}$ as compared to the SAF system and non-agitated samples. The prevalence of chemical activation in the ultrasonic group over the SAF group was almost 3 times higher, 3.11 to 1.20, respectively. The Kruskal-Wallis rank sum test revealed there is a statistically significant difference in distributions between the groups.

Conclusions. Both SAF and ultrasonics activate NaOCl. Ultrasonic agitation provided higher chemical activation of $\mathrm{NaOCl}$ solution than the SAF. The use of ultrasonic agitation of $\mathrm{NaOCl}$ in endodontic treatment will allow us to obtain better long-term clinical results.

Key words: NMR, sodium hypochlorite, endodontics, Self-Adjusting File, ultrasonics 


\section{Introduction}

Sodium hypochlorite $(\mathrm{NaOCl})$ is the most commonly used irrigant in endodontic treatment. Coolidge introduced it as early as in $1919 .{ }^{1}$ It is an inorganic compound with the chemical formula $\mathrm{NaOCl}$. Commonly referred to as bleach, it is actually a diluted aqueous solution of $\mathrm{NaOCl}$. It has numerous applications ranging from an oxidizing and chlorinating agent in organic synthesis (used in the chemical industry) to water treatment, bleaching and disinfection.

In dentistry, $\mathrm{NaOCl}$ is used in the form of dilute aqueous solutions with concentrations varying from $0.1 \%$ to $6.0 \%$. Being a highly oxidizing compound, it shows suitable properties for dissolving remnants of dental pulp as well as acting as an antimicrobial agent. ${ }^{2}$ These features prompted the use of aqueous $\mathrm{NaOCl}$ in endodontics.

Pécora et al. reported that $\mathrm{NaOCl}$ exhibits a dynamic equilibrium in an aqueous solution, according to the equation ${ }^{3}$ :

$$
\begin{gathered}
\mathrm{NaOCl}+\mathrm{H}_{2} \mathrm{O} \Leftrightarrow \mathrm{NaOH}+\mathrm{HOCl} \Leftrightarrow \\
\Leftrightarrow \mathrm{Na}^{+}+\mathrm{OH}^{-}+\mathrm{H}^{+}+\mathrm{ClO}^{-}
\end{gathered}
$$

As an ionic compound, $\mathrm{NaOCl}$ dissociates in water to sodium cation $\left(\mathrm{Na}^{+}\right)$and hypochlorite anion $\left(\mathrm{ClO}^{-}\right)$, which is in equilibrium with its protonated form $(\mathrm{HOCl})$. Both hypochlorous acid and the hypochlorite anion are strong oxidizing agents. $\mathrm{HClO}$ and $\mathrm{ClO}^{-}$have been reported to react with proteins, amino acids, peptides, and lipids. Estrela suggests $\mathrm{NaOCl}$ acts as a dissolving agent for organic matter, e.g., fats. ${ }^{4}$

An ultrasonic wave is an acoustic wave which transmits energy of a vibrating file to the irrigating agent. Waves in the 20,000-25,000 Hz frequency range, which cause several physical and biological effects, are used in endodontics. The increase of energy in the system treated with ultrasonics results in heating of the surrounding fluid, which subsequently results in a better bactericidal effect. ${ }^{5}$ The presence of cavitation and microstreaming effects is equally significant. The emerging waves disrupt bacterial cells and eliminate necrotic remnants. This mixing of the fluid and its turbulent flow has a significant influence on the efficacy of root canal irrigation. ${ }^{6,7}$

The Self-Adjusting File (SAF) is a rotary system for mechanical instrumentation. It is also the only system that enables instrumentation and irrigation at the same time. ${ }^{8}$ This is a hollow cylinder, made of Ni-Ti alloy with fusiform holes along the entire length. ${ }^{9}$ The file can compress and decompress according to the topography and morphology of the treated canal. Two sizes, $1.5 \mathrm{~mm}$ and $2 \mathrm{~mm}$ in diameter, are available. ${ }^{10}$ Action of the SAF is based on back and forth sliding motions in the vertical axis. The RDT3 head connected to an endodontic motor with the speed set to 3,000-5,000 rpm is used for the SAF. ${ }^{10,11}$ The file is connected to a VATEA (ReDent Nova, Ra'anana, Israel) pump with a silicon tube, which delivers the irrigant along the entire length of the root canal during continuous instrumentation with a speed adjustable in the $1-10 \mathrm{~mL} / \mathrm{min}$ range. ${ }^{12-14}$ It is recommended to fill the pump with $\mathrm{NaOCl}$ or ethylenediaminetetraacetic acid (EDTA) solution. ${ }^{10,12}$ The efficacy of $\mathrm{NaOCl}$ and EDTA in removing the smear layer and dentin using SAF has been proved and is not dependent on the concentration of the agent, even in the apical $1 / 3$ of the canal. ${ }^{12,15}$ It is advised to work with SAF in the canal about $4 \mathrm{~min}-2$ cycles of $2 \mathrm{~min}$ for 1 root canal with a short pause for recapitulation. ${ }^{16-18}$ In our study, Endostation (ReDent Nova, Israel) was used. It combines an endodontic motor with the VATEA pump in one device.

According to Tiong and Price, during ultrasonic agitation, hypochlorous acid undergoes homolysis with formation of a hydroxyl radical and a chlorine radical. ${ }^{19}$ The homolytic processes occur when energy is delivered to $\mathrm{HOCl}$ molecules. This can be achieved in many different ways, e.g., under UV irradiation as reported by Zeng et al. ${ }^{20}$ The resulting radicals are a species highly reactive towards a wide range of biochemical compounds - proteins and glycolipids - leading to the degradation of biological matter. ${ }^{21}$ The chemical equation of homolytic degradation is presented below:

$$
\mathrm{HOCl} \rightarrow \mathrm{HO}^{\bullet}+\mathrm{Cl}^{\cdot}
$$

One of the first investigations to quantify the action of $\mathrm{NaOCl}$ was described by Austin and Taylor in $1918 .^{22}$ The authors measured the amount of chlorine remaining in the solution when exposed to normal vs necrotic tissue. The amount of remaining chlorine directly corresponded to its tissue-dissolving capacity. As $\mathrm{NaOCl}$ dissolved the tissue, chlorine levels decreased. The amount of chlorine remaining in the solution was measured indirectly on the basis of the amount of sodium thiosulfate used to reduce chlorine in the solution.

Activation of $\mathrm{NaOCl}$ can be considered 2-fold: physical activation wherein the turbulence of the flow is enhanced, and chemical activation based on $\mathrm{HOCl}$ degradation to highly reactive radical species. The rationale for the current experiment is that a quantitative evaluation of an oxidized product will help measure the oxidative potential of $\mathrm{NaOCl}$ at a given time. Selective oxidation of an organic compound with $\mathrm{NaOCl}$ may serve as a useful method to estimate its oxidation potential. Hence, the aim of this experiment was to evaluate the chemical activation of $\mathrm{NaOCl}$ quantitatively by measuring the capacity of the irrigant to oxidize 9-fluorenol as a model organic compound.

\section{Material and methods}

\section{Experimental setup}

All chemicals used in this study were obtained from commercial sources and used as such, without further purification. The following chemicals were used (name, purity, 
additives if present, source): $\mathrm{NaOCl}, 5.25 \mathrm{wt} \%$ aqueous solution (Cerkamed, Stalowa Wola, Poland); 9-fluorenol, 96\% (Sigma-Aldrich, St. Louis, USA); ethyl acetate, $>98 \%$ (POCH S.A., Gliwice, Poland); tetra- $n$-butylammonium bromide, 99\% (Sigma-Aldrich); chloroform-d ${ }_{3}\left(\mathrm{CDCl}_{3}\right)$, 99.8 atom\% D, with $0.5 \mathrm{wt} \%$ silver foil as stabilizer and $0.03 \%$ (v/v) tetramethylsilane (TMS) (Sigma-Aldrich).

${ }^{1} \mathrm{H}$ NMR spectra were recorded on a Varian VNMRS $500 \mathrm{MHz}$ NMR spectrometer (Varian, Atlanta, USA) in $\mathrm{CDCl}_{3}$, using TMS as an internal standard for chemical shift calibration. All chemical shifts are reported in ppm. Armar Chemicals 5 mm NMR Tubes (5HP type) (Armar Chemicals, Döttingen, Switzerland) were used. Concentration under reduced pressure was carried out with a Heidolph rotary evaporator (Heidolph, Schwabach, Germany).

Due to the comparative character of the study, all possible measures were taken to ensure that all procedures were carried out as similarly as possible while evaluating both $\mathrm{NaOCl}$ activation methods. Each reading was done in triplicate and each result given as an average, along with standard deviation (SD) from the 3 readings.

\section{Sodium hypochlorite activation}

A $12 \mathrm{~mL}$ glass vial with a plastic cap was used to fill $10 \mathrm{~mL}$ samples of $5.25 \%$ (w/w) aqueous solution of $\mathrm{NaOCl}$. For each activation method, 2 samples of the $\mathrm{NaOCl}$ stock solution were prepared as mentioned above. Activation was carried out by submerging the respective system in the sample for a 4-minute period. The SAF system - a $1.5 \mathrm{~mm}$ diameter and $25 \mathrm{~mm}$ length file - was used at a speed of 5,000 rpm, with the RDT3 head connected to a handpiece on the Endostation (ReDent Nova) with an adjustable rotary speed setting, according to the manufacturer's instructions. Constant irrigant flow was not supplied to SAF during the study. For ultrasonic activation, an ISO 20 K-file (Woodpecker, China) connected to an endodontic adapter (Endochuck 120', Woodpecker, China) and a handpiece on an ultrasound device (Woodpecker UDS-P LED) with the endodontic function turned on (only the 'E' light was on and the power was at first grade, according to the user's manual).

\section{Reaction between sodium hypochlorite and 9-fluorenol}

Each reaction was carried out in a $12 \mathrm{~mL}$ glass vial equipped with a plastic cap and a magnetic stirring bar. Following a procedure modified from Mirafzal et al., ${ }^{23}$ 9-fluorenol (185 mg, $1.02 \mathrm{mmol}$ ) was dissolved in ethyl acetate $(1.5 \mathrm{~mL})$. Next, tetra- $\boldsymbol{n}$-butylammonium bromide (30 mg, $0.0931 \mathrm{mmol}, 9 \mathrm{~mol} \%$ ) was added as a solid in one portion. The tested sample of $\mathrm{NaOCl}$ solution $(1.5 \mathrm{~mL})$ was added to the resulting solution in one portion. The reaction mixture was stirred for $30 \mathrm{~min}$. Using a syringe, a portion of the organic layer $(1 \mathrm{~mL})$ was transferred from the vial to a $10 \mathrm{~mL}$ glass round-bottom flask. The solution was concentrated under reduced pressure to dryness, using a rotary evaporator. $\mathrm{CDCl}_{3}(0.7 \mathrm{~mL})$ was added to the soobtained residue, resulting in the formation of a clear solution. The absolute concentration of the NMR sample, given with respect to the organic compound used, was equal to $1.45 \mathrm{~mol} / \mathrm{dm} .{ }^{3}$ To prepare for ${ }^{1} \mathrm{H}$ NMR analysis, the solution was then transferred to an NMR tube using a plastic syringe, and the tube was closed with a plastic cap.

\section{Statistical analysis}

The statistical analysis was made using an open source statistical environment R v. 3.5.1. ${ }^{24}$ (https://www.R-project. org/). The Kruskal-Wallis rank sum test was available as krustal.Test function from $\mathrm{R}$ package, including test statistics, p-value and number of degrees of freedom (df), follows in implementation the theoretical results from Hollander and Wolfe. ${ }^{25}$

\section{Results}

\section{Model for the study}

The reaction under assessment is the phase-transfercatalyzed oxidation of 9-fluorenol with $\mathrm{NaOCl}$ (Fig. 1). ${ }^{23,26}$ The rationale behind picking it as a model reaction is given in the Discussion section. The experiment was performed on 3 samples: commercially available non-activated $\mathrm{NaOCl}$ solution, $\mathrm{NaOCl}$ solution subjected to ultrasonic activation and $\mathrm{NaOCl}$ solution activated with the SAF system.

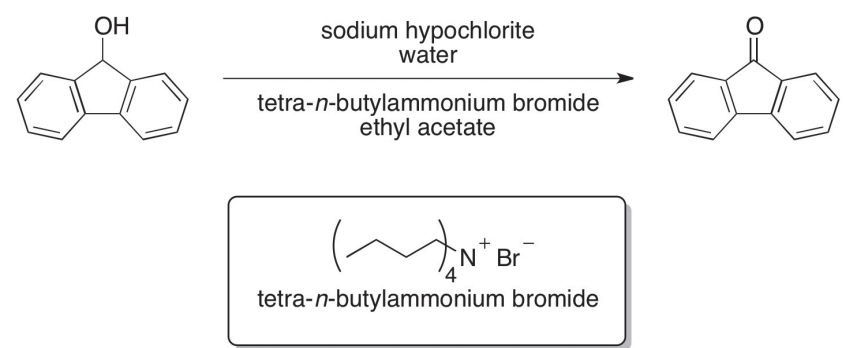

Fig. 1. Equation of the model reaction used in this study: oxidation of 9-fluorenol with sodium hypochlorite and tetra- $n$-butylammonium bromide as a phase-transfer catalyst

\section{${ }^{1} \mathrm{H}$ NMR spectroscopy}

${ }^{1} \mathrm{H}$ NMR spectra were recorded in $\mathrm{CDCl}_{3}$ at $298 \mathrm{~K}\left(25^{\circ} \mathrm{C}\right)$ and 499.93 $\mathrm{MHz}$. A standard proton pulse sequence (s2pul) was used, with relaxation delay at $1.000 \mathrm{~s}$, pulse at $45.0^{\circ}$, acquisition time at $2.045 \mathrm{~s}$ and $8,012.8 \mathrm{~Hz}$ spectral width. Acquisition of each spectrum comprised 16 scans.

The spectra were processed using iNMR Reader software (Mestrelab Research, Santiago de Compostela, Spain). The raw NMR files (FIDs) were subjected to automatic Fourier transform (FT) with FT size equal to 64k. Automatic 


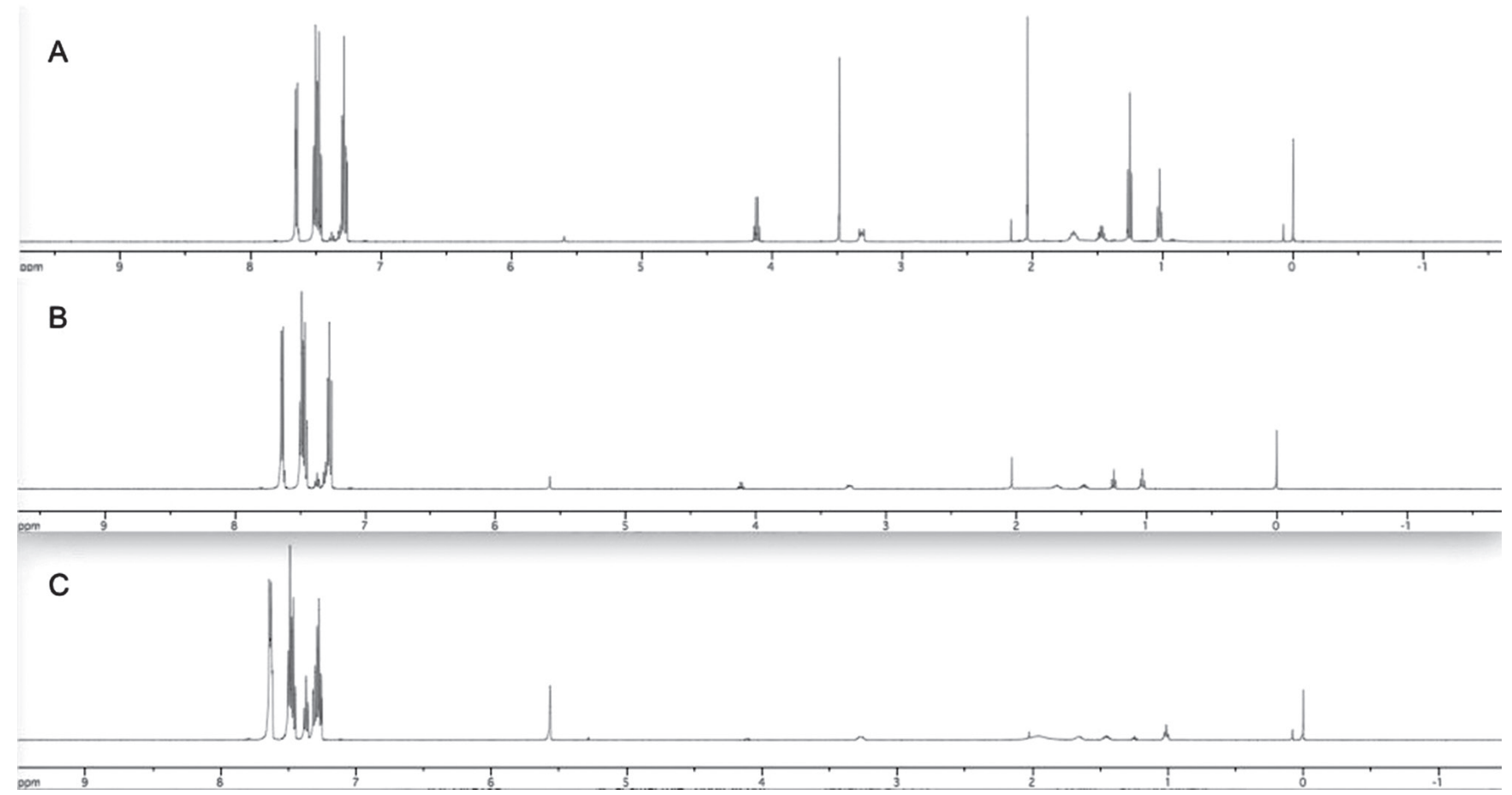

Fig. 2. Comparison of whole ${ }^{1} \mathrm{H}$ NMR spectra obtained from the evaluation experiments carried out on: (A) non-activated $\mathrm{NaOCl}$; (B) $\mathrm{NaOCl}$ activated with the SAF system; (C) NaOCl activated with ultrasonics

baseline correction for a 1D spectrum, implemented in the iNMR Reader software, was applied to each spectrum, setting the baseline intensity to 0 and thus allowing to reliably integrate the peaks. Full view of the obtained ${ }^{1} \mathrm{H}$ NMR spectra, 1 for each kind of samples examined, is presented in Fig. 2. The spectra are shown in the range between $9.0 \mathrm{ppm}$ and $0.0 \mathrm{ppm}$, with TMS signal at $0.0 \mathrm{ppm}$.

The analytically useful peaks are in the $7.8 \mathrm{ppm}$ to $7.0 \mathrm{ppm}$ (aromatic region) and $5.6 \mathrm{ppm}$ to $5.5 \mathrm{ppm}$ (benzylic protons) range. The signals of chemical shifts below $5.0 \mathrm{ppm}$ include peaks derived from hydrogen atoms in: ethyl acetate (solvent in the reaction), tetra- $n$-butylammonium bromide (catalyst), water and TMS (NMR chemical shift standard). The peaks in the region below $5.0 \mathrm{ppm}$ were not relevant for the study and have been omitted in Fig. 3 for clarity. Both aromatic and benzylic signals were integrated, providing the relative ratio of the total areas of the peaks. The comparative spectroscopic analyses of reactions mixtures obtained from respective solutions are showed in Fig. 3.

\section{Chemical concept of the study}

The chemical concept applied here is that aromatic protons can serve as an internal reference to evaluate the extent of oxidation and therefore the effectiveness of $\mathrm{NaOCl}$ activation. The interpretation of the changes occurring in the mixture upon oxidation is straightforward, as both the 9-fluorenol and 9-fluorenone have aromatic protons, while only the 9-fluorenol has a benzylic proton (Fig. 4). Upon oxidation, the number of aromatic protons (and thus the integration of the aromatic region) is equal both in the starting material and the product and is unchanged during the oxidation. ${ }^{27,28}$ The variable here is the benzylic signal, which decreases in its intensity (and integration) upon oxidation.

The ratio of integration values of signals derived from benzylic protons to aromatic protons may be correlated with the efficiency of 9-fluorenol oxidation and establishes the basis for evaluating the $\mathrm{NaOCl}$ activation method. The higher benzylic-to-aromatic signal ratio, the less efficient was the oxidation of 9-fluorenol to 9-fluorenone. Less efficient oxidation of the starting material means that a smaller amount of hypochlorite was left in the solution after its activation, which points to a higher extent of the decomposition of hypochlorite upon activation. This is an indication of better efficacy of $\mathrm{NaOCl}$ and hence a more effective method to activate the irrigant. To convey the idea more clearly, the logical sequence behind it is summarized graphically in Fig. 5.

\section{Numerical results of the study}

The numerical results of the analyses are presented in Table 1. As each experiment was done 3-fold, 3 entries for each activation mode are provided. As aforementioned, the number of aromatic protons remain unaffected upon oxidation, so the integration of their signals can serve as an internal standard for determining the integration ratio. ${ }^{29}$ The integration of the aromatic region was then set by default to 1.00. As all further discussion is based on the integration ratios, setting the aromatic region 

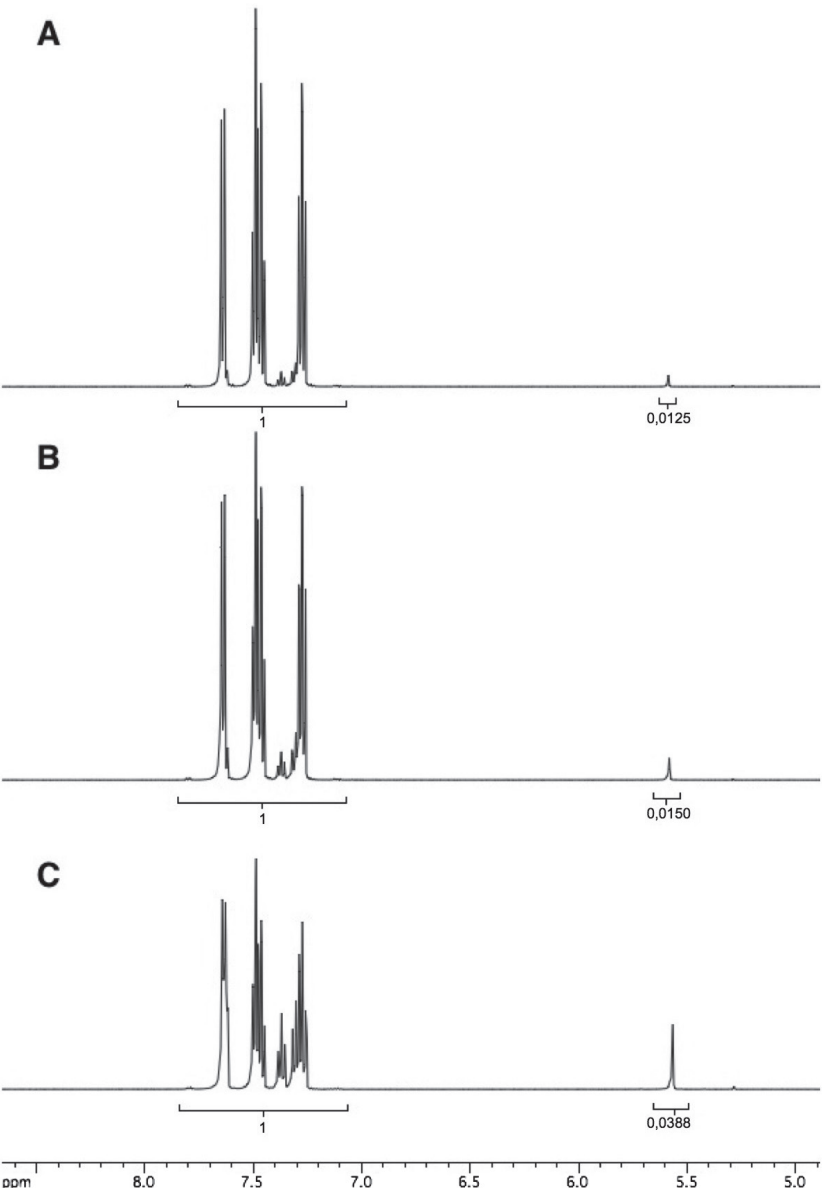

Fig. 3. Comparison of ${ }^{1} \mathrm{H}$ NMR spectra obtained from the evaluation experiments carried out on: (A) non-activated $\mathrm{NaOCl}$; (B) $\mathrm{NaOCl}$ activated with the SAF system; (C) NaOCl activated with ultrasonics. The peak in the 5.60-5.50 region corresponds to the benzylic hydrogen atom in the structure of 9-fluorenol. The region below 5.0 ppm was omitted for clarity. Each integration value given below the peak is an average determined from 3 experiments conducted on every sample

integration to 1.00 makes it easier to evaluate and discuss the results.

With this in mind, there is no need to reference the integration of signals against the internal standard used, i.e., TMS. The additive of TMS in the commercial deuterated solvent was used only for calibrating the chemical shift of the observed signals, with TMS having the chemical

Table 1. Results of the spectroscopic studies

\begin{tabular}{|l|c|c|c|c|}
$\begin{array}{c}\text { Activation } \\
\text { mode }\end{array}$ & $\begin{array}{c}\text { Benzylic-to-aromatic } \\
\text { signals integration ratio }\end{array}$ & Average & $\begin{array}{c}\text { Standard } \\
\text { deviation (SD) }\end{array}$ & $\begin{array}{c}\text { Recalculated } \\
\text { integration ratio' }\end{array}$ \\
\hline No activation & $\begin{array}{l}0.0127: 1.00 \\
0.0122: 1.00\end{array}$ & 0.0125 & 0.0003 & 1.00 \\
& $0.0125: 1.00$ & & & 1.20 \\
SAF & $0.0154: 1.00$ & 0.0150 & 0.0006 & \\
& $0.0152: 1.00$ & & & 3.11 \\
\hline & $0.0143: 1.00$ & & & \\
\hline
\end{tabular}

${ }^{1}$ The benzylic-to-aromatic signals integration ratio, recalculated with respect to the value of the "no activation" ratio equal to 1.00

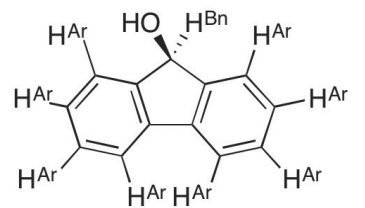

9-fluorenol<smiles>O=C1c2c(Br)c(Br)c(Br)c([125I])c2-c2c([125I])c(Br)c(Br)c(Br)c21</smiles>

9-fluorenone

Fig. 4. Chemical structures of 9-fluorenol and 9-fluorenone, with hydrogen $(\mathrm{H})$ atoms described $(\mathrm{Ar}=$ aromatic, $\mathrm{Bn}=$ benzylic)

higher benzylic-to-aromatic signal ratio

higher amount of 9-fluorenol left after the reaction

less efficient oxidation of 9-fluorenol

smaller amount of $\mathrm{NaOCl}$ left after activation

more $\mathrm{NaOCl}$ decomposed during activation

better activation of $\mathrm{NaOCl}$

better method for the activation of $\mathrm{NaOCl}$ solution

Fig. 5. Summary of the chemical concept behind the proposed evaluation

shift of $0.00 \mathrm{ppm}$. Tetramethylsilane would not have been a reliable reference for the integration due its volatility ${ }^{30}$ and hence tendency to change its concentration over time, making it an invalid reference for any quantitative studies.

The use of another chemical shift standard widely used in molecular medicine studies, namely 3-(trimethylsilyl)2,2,3,3-tetradeuteropropionic acid (TSP), would not be possible due to the fact that TSP is insoluble in deuterated chloroform which was the deuterated solvent used in this study. Deuterated chloroform was picked as a deuterated solvent of choice due to its capability to dissolve the organic compounds well, both the substrate (9-fluorenol) and the product 
(9-fluorenone) as well as any amount of the catalyst left in the organic phase during the extraction. ${ }^{27,28,31}$ Moreover, the use of TSP could lead to misleading results as TSP tends to be unstable in the presence of oxidative agents. If any traces of $\mathrm{NaOCl}$ had been left after the extraction process (which is unlikely but cannot be excluded), TSP would have got oxidized, hence making its use as a standard invalid.

In all experiments, the benzylic-to-aromatic ratios were found to be between 0.0122:1.00 and 0.0396:1.00. That observation was expected, as the integration should have fallen within the 0.1250 for 9-fluorenol (equal to 1:8 ratio, with 1 benzylic proton and 8 aromatic protons) and 0 for 9-fluorenone (0:8 ratio, with no benzylic protons and 8 aromatic protons) bracket. Importantly, none of the ratios were equal to 0 , as that would mean 9-fluorenol was oxidized completely which would preclude any qualitative or quantitative conclusions being drawn.

For each activation mode, an average ratio was determined from 3 experiments, along with its SD. The integration ratios were then recalculated with respect to the "no activation" ratio set to 1.00 . The ratio values for the SAF and ultrasonic activation modes were found to be 1.20 and 3.11, respectively.

Differences in the results between the examined groups of samples are clearly visible in Fig. 6. The obtained integration ratios of all results in the SAF and ultrasonics groups are higher than the values for a non-activated group.

\section{Statistical analysis results}

Taking into account the means and SDs of benzylic-toaromatic signals integration ratio between groups, our hypothesis states that their distribution is not equal. Due to the fact that there is no way to reliably test for normality when we have 3 observations per group, a non-parametric approach is used. The null hypothesis that the cumulative distribution function in all 3 groups is equal is tested against the alternative hypothesis that at least 2 out of 3 cumulative distribution functions in the groups are different. The hypotheses are tested using ANOVA on ranks, i.e., using the Kruskal-Wallis rank-sum test. The value of the test statistics, which under the null hypothesis has a $x^{2}$ distribution with $2 \mathrm{df}$, is 7.2. It follows that the $\mathrm{p}$-value in this test is equal to 0.02732372 , which is lower than the 0.05 significance level. The null hypothesis is rejected, thus at the 0.05 significance level there is a statistically significant difference in distributions between the groups.

It is important to note, that in this case the usual interpretation of Kruskal-Wallis rank sum test using medians is not possible. For the test to be interpreted in terms of medians, we should verify first that all 3 distributions come from the same family of location-scale distributions. This is not possible with the available data, due to the small number of observations. For the same reason, it is also impossible to perform a non-parametric post-hoc analysis using the Wilcoxon rank sum test.

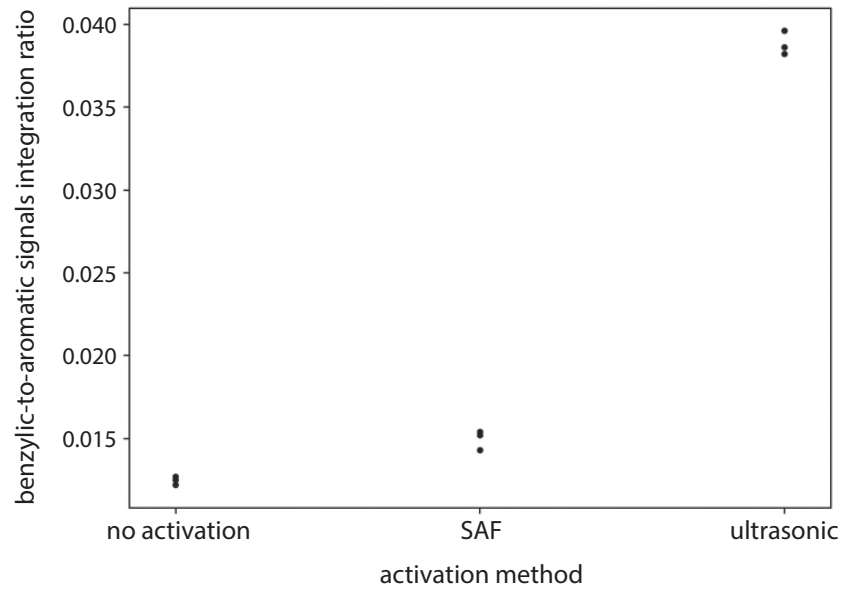

Fig. 6. A graph presenting data points from the spectroscopic study. The results both in the SAF and ultrasonics groups clearly predominate over the control group (no activation). The results in the ultrasonics group are more than 3-fold higher in comparison to these in the SAF group

By looking at the data points in Fig. 6 and knowing that the continuous distribution functions are different, we can postulate that they do differ in mean.

\section{Discussion}

Stojicic et al. suggested several methods for improving efficacy of $\mathrm{NaOCl}$. Changes in concentration, temperature, agitation, increase of $\mathrm{pH}$, and prolonged contact time are some of them. ${ }^{32}$ Moorer and Wesselink stressed the impact of mechanical agitation to be the most significant mode of $\mathrm{NaOCl}$ activation. They claim fluid flow is the key for effective tissue dissolution and disinfection as well as emphasize that ultrasounds ensure the best quality of turbulent flow. ${ }^{33}$ An increase in flow and more turbulence enables the solution to reach hardly accessible areas and therefore improve efficacy. Sáinz-Pardo et al. also provide evidence that ultrasonic agitation ensures proper fluid flow throughout the working length of a root canal. ${ }^{34} \mathrm{Be}-$ sides fluid dynamics, the exact mechanism responsible for the improved efficacy is not clear. ${ }^{35}$ This is the first investigation of its kind to evaluate whether a chemical activation of $\mathrm{NaOCl}$ also occurs during agitation.

To evaluate the methods for hypochlorite activation, we searched the chemical literature for reactions which use $\mathrm{NaOCl}$ solutions as a reagent. We preferred a reaction that did not take long to carry out in order to shorten the evaluation as much as possible. Other criteria that needed to be met included the following: easy reaction set-up (ideally no specialized glassware or equipment), mild conditions (preferably room temperature, atmospheric pressure, no need for the use of inert gases like argon or nitrogen), inexpensive and easily commercially available chemicals (including the starting materials, solvents and optionally catalysts) as well as the possibility to carry out the evaluation using an analytical method yielding readily interpretable 
and unequivocal results. After a detailed literature survey, we picked the phase-transfer-catalyzed oxidation of 9-fluorenol with $\mathrm{NaOCl}$ as the model reaction.

The role of $\mathrm{NaOCl}$ solution is to provide hypochlorite anions $\left(\mathrm{ClO}^{-}\right)$, which serve as an oxidant towards benzylic alcohol. Importantly for the evaluation of oxidation potential, hypochlorite reacts with 9-fluorenol selectively, affording solely the oxidation product - 9-fluorenone. 9-fluorenol is not prone to spontaneous oxidation neither in pure oxygen nor in the air, even upon prolonged storage. These properties made the quantitative evaluation of oxidation product exclusive to $\mathrm{NaOCl}$, and hence valid. Moreover, it facilitates handling of 9-fluorenol, as no specialized chemical skills or sophisticated equipment is required.

Among the many variants of 9-fluorenol oxidations, the one chosen by us is preferable also because it does not require the presence of expensive, metal-based catalysts, elevated temperature or irradiation. For an effective execution of 9-fluorenol oxidation with hypochlorite, it is sufficient to make use of inexpensive and easily applicable phase-transfer catalysis (PTC). ${ }^{31}$ The method, originally developed in the 1960s, is particularly useful for reactions occurring in 2-phase systems, i.e., in reaction mixtures containing 2 immiscible (or miscible to a limited extent) layers. For example, such layers may be made up of a reagent aqueous solution (in our case: aqueous solution of $\mathrm{NaOCl}$ ) and a solution of the starting organic material (here: 9-fluorenol) in an organic solvent immiscible with water (e.g., ethyl acetate). The reaction between the organic substrate and the inorganic reagent (hypochlorite anion) takes place at the interphase between those 2 layers. For the oxidation to proceed efficiently, both the substrate and the oxidant must come together in the interphase at the same time. Here a phase-transfer catalyst comes in useful. The PTC catalysts usually contain a heteroatom (particularly nitrogen), in the form of a cationic ammonium species with a general formula of $\mathrm{R}_{4} \mathrm{~N}^{+}$, where $\mathrm{R}$ is an organic group, most commonly an aliphatic chain. Such a structure has a dual nature in terms of polarity: the cationic nitrogen atom serves as the polar (hydrophilic) center, while the aliphatic hydrocarbon chains are highly non-polar (hydrophobic, but with high affinity to the organic layer). This duality makes it possible for the cation of the catalyst to be transported to both the organic and aqueous layers, efficiently delivering the hypochlorite anion from the aqueous layer to the interphase with the organic layer. In this study, tetra- $n$-butylammonium bromide was used as the phase-transfer catalyst.

Having an appropriate model reaction at hand, we embarked on the search for a method for both a qualitative and a quantitative analysis of the reaction mixture composition, i.e., the identity and content of the substrate and product. We chose nuclear magnetic resonance (NMR) spectroscopy for this purpose. The NMR spectroscopy is one of the most important research techniques used to investigate the structure, content and interactions of organic compounds. The method is basically based on the phenomenon of energy transitions occurring within the nuclei of atoms when an external magnetic field is applied. By investigating the electromagnetic signals in this process and working them out mathematically, a so-called NMR spectrum can be obtained. The NMR method we decided to use was proton NMR ( ${ }^{1} \mathrm{H}$ NMR), as it allows one to obtain qualitative and quantitative information on protons (hydrogen nuclei) in the organic compounds structure present in the analyzed mixture.

Only a few reports on the use of spectroscopic methods in endodontic research have been published, all of them being relatively recent. A study by Sireesha et al. on the comparison of micro and nano substances used as temporary intracanal dressings was based on infrared spectroscopy (Fourier-transform infrared spectroscopy - FTIR) to analyze the interactions between nanoparticles. ${ }^{36}$ The conclusion from the study was that the tested nano-calcium hydroxide and nano-chitosan compounds are superior to ordinary calcium hydroxide and chitosan both in terms of better penetration of dentinal tubules and lower susceptibility to root fracture. One can find an example of the use of mass spectrometry (MS) in a study by Chávez de Paz et al. ${ }^{37}$ An evaluation of the coexistence of Enterococcus faecalis bacteria strains with other bacteria within the root canal system has showed that in this case bacteria can interact synergistically as well as antagonistically. X-ray spectroscopy is another example of spectroscopy used in endodontic research, and in particular wavelength-dispersive X-ray spectroscopy (WDXS or WDS) used in the Han study to assess the calcium and silicon uptake by dentin from Biodentine and MTA. ${ }^{38}$ The study shows that the dentin adjacent to a given material exhibited greater influence of calcium and silicon from the Biodentine material.

By using the concept of spectroscopic data analysis described in the Results section, we were able to qualitatively and quantitatively compare the activation methods. Based on the ${ }^{1} \mathrm{H}$ NMR integration ratios recalculated with reference to the ratio obtained for non-activated $\mathrm{NaOCl}$, the occurrence of chemical activation of hypochlorite by both the SAF and ultrasonics was confirmed. Quantitatively, the ultrasonic activation was over 2 times more effective compared to the SAF activation (1.2-fold activation for SAF compared to 3.1-fold activation for ultrasonics).

All the results obtained in the SAF and ultrasonic groups predominated these in the non-activated group. What is more, all results in the ultrasonic group were higher than those measured in the SAF group. The consequence and reproducibility in each group with a low SD value lays a basis for the use of this method in other $\mathrm{NaOCl}$-related studies and analyses in the future. Similar experiments on other $\mathrm{NaOCl}$ agitation methods would have a worthwhile contribution in understanding their clinical efficacy.

It is worth noticing that another dentistry-related study on $\mathrm{NaOCl}$ capacity for oxidation can be found 
in literature ${ }^{39}$ However, it used a non-spectroscopic method for $\mathrm{NaOCl}$ analysis, namely a redox titration called iodometry. Zehnder assessed the buffered and unbuffered solution of $\mathrm{NaOCl}$ for tissue dissolution. ${ }^{39}$ However, the disadvantage of that approach was that potassium iodide (KI; used as a titrating solution) is known to be reactive not only towards $\mathrm{NaOCl}$, but also other oxidants present in the solution. This appears even more perspicuous when the equations of $\mathrm{NaOCl}$ comproportionation (Equation 1) as well as non-selectivity of potassium iodide oxidation (Equations 2 and 3) are taken into account.

(1) $3 \mathrm{NaOCl} \rightarrow 2 \mathrm{NaCl}+\mathrm{NaClO}_{3}$

(2) $\mathrm{NaClO}_{3}+6 \mathrm{KI}+3 \mathrm{H}_{2} \mathrm{O} \rightarrow \mathrm{NaCl}+3 \mathrm{I}_{2}+6 \mathrm{KOH}$

(3) $\mathrm{NaOCl}+2 \mathrm{KI}+\mathrm{H}_{2} \mathrm{O} \mathrm{NaCl}+\mathrm{I}_{2}+2 \mathrm{KOH}$

Sodium hypochlorite $(\mathrm{NaOCl})$ is known to comproportionate into sodium chlorate $\left(\mathrm{NaClO}_{3}\right)$ and sodium chloride while in aqueous solutions, especially over prolonged storage. Importantly, both $\mathrm{NaOCl}$ and $\mathrm{NaClO}_{3}$ are able to oxidize potassium iodide. The titration result may then be false due to lack of selectivity.

The reactions used in our study display specificity towards $\mathrm{NaOCl}$, with 9-fluorenol being selectively oxidized by it. Despite a great number of works on chlorine-based oxidants, $\mathrm{NaClO}_{3}$ has never been found to oxidize any secondary alcohols like 9-fluorenol.

In conclusion, a spectroscopy-based protocol for a quantitative evaluation of activation of $\mathrm{NaOCl}$ was proposed and successfully implemented. The comparative ${ }^{1} \mathrm{H}$ NMR data, derived from the experiments on the irrigant capacity to oxidize 9-fluorenol, unequivocally showed that both SAF and ultrasonics activate $\mathrm{NaOCl}$. In addition, it was showed that ultrasonic agitation provided better chemical activation of the $\mathrm{NaOCl}$ solution than the SAF.

From a medical perspective, it is worthwhile to point out that any contact between an ultrasonic file with canal walls diminishes the activation effect. ${ }^{40}$ This is the main impediment to achieving proper ultrasonic activation on the whole working length in severely curved canals.

On another concluding note, we believe that such an interdisciplinary approach towards solving challenges on the border of medicine and science will soon become an important area for research and such results may quickly become clinically relevant. In this case, the significance of the study lies in providing a dental practitioner with specific information on choosing the best way for $\mathrm{NaOCl}$ activation, making canal disinfection as thorough as possible and increasing the efficiency as well as the long-term results of endodontic treatment in the clinic.

A molecular approach in exploring the dental field may give extraordinary opportunities in future scientific projects in this area of medicine. Nowadays, microbiological and clinical studies underlie the majority of new techniques and devices being introduced into the market and, in consequence, the dental practice. However, it is molecular medicine and experimental approach that explain the fundamental aspects of biological and chemical mechanisms behind these developments and boosts the understanding of everyday activities undertaken by physicians and dentists. The described influence of the SAF motion and ultrasonic wave on changes in the molecular composition of $\mathrm{NaOCl}$ solution should make one aware that any step taken during a clinical procedure may hinder or improve the overall outcome. Advantageous properties of $\mathrm{NaOCl}$ for endodontics that are strengthened by additional activation methods like ultrasonics can be correctly understood only by means of a thorough experimental analysis. The mechanisms behind the observed macroscopic phenomena in the clinical environment are often comprehensively understandable only at the molecular level.

\section{ORCID iDs}

Hubert Gołąbek (1) https://orcid.org/0000-0003-0840-2752 Krzysztof Mariusz Borys (D) https://orcid.org/0000-0002-6131-4236 Meetu Ralli Kohli (D) https://orcid.org/0000-0003-2788-8903 Katarzyna Brus-Sawczuk (D) https://orcid.org/0000-0003-3139-0112 Izabela Strużycka (D) https://orcid.org/0000-0002-7058-3614

\section{References}

1. Coolidge ED. The diagnosis and treatment of conditions resulting from diseased dental pulps. J Am Dent Assoc. 1996;6(4):337-349.

2. Senia ES, Marshal FJ, Rosen S. The solvent action of sodium hypochlorite on pulp tissue of extracted teeth. Oral Surg Oral Med Oral Pathol. 1971;31(1):96-103.

3. Pécora JD, Sousa-Neto MD, Estrela C. Soluções irrigadoras auxiliares do preparo do canal radicular. In: Estrela C, Figueiredo JAP, eds. Endodontia - Princípios biológicos e mecânicos. São Paulo, Brazil: Artes Médicas; 1999:552-569.

4. Estrela C, Estrela CR, Barbin EL, Spanó JC, Marchesan MA, Pécora JD. Mechanism of action of sodium hypochlorite. Braz Dent J. 2002;13(2): 113-117.

5. Gołąbek H, Duszkiewicz P, Szutowska A, Mielko E, Strużycka I. Review of techniques and current possibilities of root canal irrigation. Dental Forum. 2015;43:85-92.

6. Baker NA, Eleazer PD, Averbach RE, Seltzer S. Scanning electron microscopic study of the efficacy of various irrigating solutions. J Endod. 1975;1(4):127-135.

7. Beer R, Baumann MA, Kielbassa AM. Ilustrowane kompendium endodoncji. Lublin, Poland: Czelej; 2009.

8. Gołąbek H, Brus-Sawczuk K, Strużycka I. The Self Adjusting File - a review. New system, a new look into the root canal space? Dental Forum. 2014;42:89-94.

9. Solomonov M. Eight months of clinical experience with the SelfAdjusting File System. J Endod. 2011;37(6):881-887.

10. De-Deus G, Souza EM, Barino B, Maia J, Zamolyi RQ, Reis C, Kfir A. The Self-Adjusting File optimizes debridement quality in ovalshaped root canals. J Endod. 2011;37(5):701-705.

11. Hof R, Perevalov V, Eltanani M, Zary R, Metzger Z. The Self-Adjusting File (SAF). Part 2: Mechanical analysis. J Endod. 2010;36(4):691-696.

12. Kaya S, Yiğit-Özer S, Adigüzel Ö. Evaluation of radicular dentin erosion and smear layer removal capacity of Self-Adjusting File using different concentrations of sodium hypochlorite as an initial irrigant. Oral Surg Oral Med Oral Pathol Oral Radiol Endod. 2011;112(4):524-530.

13. Cohen S, Levin MD, Berman LH. The SAF EndoSystem: Adaptive 3-D cleaning, shaping, and disinfection. Endod Prac. 2011;4(2):34-38.

14. Block R, Supan P, Bushell A. The Self Adjusting File (SAF) System: Perspectives on a new endodontic technique. The Communicator. 2012; Winter:24-28.

15. Metzger Z, Teperovich E, Cohen R, Zary R, Paqué F, Hülsmann M. The Self-Adjusting File (SAF). Part 3: Removal of debris and smear layer: A scanning electron microscope study. J Endod. 2010;36(4): 697-702. 
16. Özer SY, Adigüzel O, Kaya S. Removal of debris and smear layer in curved root canals using Self-Adjusting File with different operation times: A scanning electron microscope study. Int Dent Res. 2011; 1(1):1-6.

17. Metzger Z, Teperovich E, Zary R, Cohen R, Hof R. The Self-Adjusting File (SAF). Part 1: Respecting the root canal anatomy - a new concept of endodontic files and its implementation. J Endod. 2010;36(4): 679-690.

18. Alves FRF, Almeida BM, Neves MA, Rôças IN, Siqueira JR Jr. Time-dependent antibacterial effects of the Self-Adjusting File used with two sodium hypochlorite concentrations. J Endod. 2011;37(10):1451-1455.

19. Tiong TJ, Price GJ. Ultrasound promoted reaction of Rhodamine B with sodium hypochlorite using sonochemical and dental ultrasonic instruments. Ultrason Sonochem. 2012;19(2):358-364.

20. Zeng Q, Fu J, Shi YT, Zhu HL. Degradation of C.I. Disperse Blue 56 by ultraviolet radiation/sodium hypochlorite. Ozone Sci Eng. 2009; 31(1):37-44.

21. Krumova K, Cosa G. Overview of Reactive Oxygen Species. Singlet Oxygen: Applications in Biosciences and Nanosciences. Vol. 1. Cambridge, UK: The Royal Society of Chemistry; 2016.

22. Austin JH, Taylor HD. Behavior of hypochlorite and of chloramine-T solutions in contact with necrotic and normal tissues in vivo. J Exp Med. 1918;27(5):627-633.

23. Mirafzal GA, Lozeva AM. Phase transfer catalyzed oxidation of alcohols with sodium hypochlorite. Tetrahedron Lett. 1998;39(40):7263-7266.

24. R Core Team. R: A language and environment for statistical computing. R Foundation for Statistical Computing, Vienna, Austria, 2018: URL https://www.R-project.org/.

25. Hollander M, Wolfe DA. Nonparametric Statistical Methods. New York USA: John Wiley \& Sons; 1973:115-120.

26. Jones CS, Albizati K. Sodium hypochlorite oxidation of 9-fluoreno to 9-fluorenone: A reaction monitored by thin layer chromatography. J Chem Educ. 1994;71:A271-A272.

27. Laudadio G, Govaerts S, Wang Y, et al. Selective $\mathrm{C}\left(\mathrm{sp}^{3}\right)-\mathrm{H}$ aerobic oxidation enabled by Decatungstate photocatalysis in flow. Angew Chem Int Ed Engl. 2018;57(15):4078-4082.
28. Xuan Q, Zhao C, Song Q. Umpolung of protons from H2O: Q metal-free chemoselective reduction of carbonyl compounds via $\mathrm{B}_{2} \mathrm{pin}_{2} / \mathrm{H}_{2} \mathrm{O}$ systems. Org Biomol Chem. 2017;15(24):5140-5144.

29. Kato R, Yoshimasa K, Egashira T, Oya T, Oyaizu K, Nishide H. A ketone/ alcohol polymer for cycle of electrolytic hydrogen-fixing with water and releasing under mild conditions. Nat Commun. 2016;7:13032.

30. Ho HA, Manna K, Sadow AD. Acceptorless photocatalytic dehydrogenation for alcohol decarbonylation and imine synthesis. Angew Chem Int Ed Engl. 2012;51(34):8607-8610.

31. Yamanaka M, Shivanyuk A, Rebek J Jr. Kinetics and thermodynamics of hexameric capsule formation. J Am Chem Soc. 2004;126(9): 2939-2943.

32. Stojicic S, Zivkovic S, Qian W, Zhang H, Haapasalo M. Tissue dissolution by sodium hypochlorite: Effect of concentration, temperature, agitation, and surfactant. J Endod. 2010;36(9):1558-1562.

33. Moorer WR, Wesselink PR. Factors promoting the tissue dissolving capability of sodium hypochlorite. Int Endod J. 1982;15(4):187-196.

34. Sáinz-Pardo M, Estevez R, De Pablo Óv, Rossi-Fedele G, Cisneros R. Root canal penetration of a sodium hypochlorite mixture using sonic or ultrasonic activation. Braz Dent J. 2014;25(6):489-493.

35. Zehnder M. Root canal irrigants. J Endod. 2006;32(5):389-398.

36. Sireesha A, Jayasree R, Vidhya S, Mahalaxmi S, Sujatha V, Kumar TSS. Comparative evaluation of micron-and nano-sized intracanal medicaments on penetration and fracture resistance of root dentin: An in vitro study. Int J Biol Macromol. 2017;104(Pt B):1866-1873.

37. Chávez de Paz LE, Davies JR, Bergenholtz G, Svensäter G. Strains of Enterococcus faecalis differ in their ability to coexist in biofilms with other root canal bacteria. Int Endod J. 2015;48(10):916-925.

38. Han L, Okiji T. Uptake of calcium and silicon released from calcium silicate-based endodontic materials into root canal dentine. Int EndodJ. 2011;44(12):1081-1087.

39. Zehnder M, Kosicki D, Luder H, Sener B, Waltimo T. Tissue-dissolving capacity and antibacterial effect of buffered and unbuffered hypochlorite solutions. Oral Surg Oral Med Oral Pathol Oral Radiol Endod. 2002;94(6):756-762.

40. Sabins RA, Johnson JD, Hellstein JW. A comparison of the cleaning efficacy of short-term sonic and ultrasonic passive irrigation after hand instrumentation in molar root canals. J Endod. 2003;29(10): 674-678. 